Pharmaciana

Vol.7, No.1, Mei 2017, Hal. 79-86

ISSN: 2088 4559; e-ISSN: 24770256

DOI: $10.12928 /$ pharmaciana.v7i1.6342

\title{
Uji sifat fisik repelan minyak atsiri kombinasi rimpang temulawak dan rimpang jahe basis cold cream
}

\author{
Siti Fatmawati Fatimah*1, Wahyu Widyaningsih², Azis Ikhsanudin ${ }^{3}$ \\ Fakultas Farmasi, Universitas Ahmad Dahlan \\ Jl. Prof. Dr. Soepomo,S.H., Janturan, Yogyakarta
}

Submitted: 28-04-2017 Reviewed: 06-05-2017 Accepted: 08-05-2017

\begin{abstract}
ABSTRAK
Rimpang jahe (Zingiber officinale Roxb. Rhizome) dan rimpang temulawak (Curcuma xanthorrhiza roxb. Rhizome) memiliki kandungan minyak atsiri yang dapat berfungsi sebagai repelan. Guna mengatasi mahalnya rimpang jahe dan sifat iritatif minyak atsiri rimpang jahe, maka dikombinasikan dengan minyak atsiri rimpang temulawak. Basis cold cream memiliki fase minyak yang lebih banyak yang dapat meningkatkan kemampuan pengikatan minyak atsiri. Adanya basis tersebut diharapkan dapat meningkatkan efek repelan. Oleh karenanya, terkait efek repelan perlu dilakukan uji sifat fisik minyak atsiri untuk memastikan kemurnian dan mutunya, kemudian sebelum dilakukan uji efek repelan, perlu dilakukan uji sifat fisik sediaan repelan untuk memperoleh formula terbaik, yaitu formula yang dapat dioleskan dengan mudah dan nyaman jika digunakan. Minyak atsiri rimpang temulawak dan rimpang jahe diisolasi dengan metode destilasi uap dan air, serta diuji sifat fisiknya, yang terdiri dari uji organoleptis, indeks bias dan berat jenis. Repelan dibuat dalam berbagai konsentrasi $2 \% \mathrm{v} / \mathrm{b}, 5 \% \mathrm{v} / \mathrm{b}, 10 \% \mathrm{v} / \mathrm{b}, 15 \% \mathrm{v} / \mathrm{b}, 20 \% \mathrm{v} / \mathrm{b}$, dan $25 \% \mathrm{v} / \mathrm{b}$, kemudian dilakukan uji daya sebar, daya lekat, dan viskositas. Semakin tinggi konsentrasi minyak atsiri menyebabkan daya sebar semakin luas, namun viskositas dan daya daya lekat semakin kecil. Formula terpilih adalah formula dengan konsentrasi $25 \%$ b/v karena memiliki daya sebar yang luas dan viskositas yang kecil sehingga dengan sedikit usaha repelan dapat dioleskan serta daya lekat yang kecil sehingga mudah untuk dituang dan dibersihkan.
\end{abstract}

Kata kunci: minyak atisiri, rimpang temulawak, rimpang jahe, repelan, uji sifat fisik.

\begin{abstract}
Ginger Rhizome (Zingiber officinale Rhizome Roxb. Rhizome) and Javanese Turmeric Rhizome (Curcuma xanthorrhiza roxb. Rhizome) contain essential oils that can serve as a repellent. In order to cut the cost and irritating nature of ginger essential oil, essential oils of Javanese Turmeric had been combined. Cold cream base has more oil phase that can improve the ability of essential oils binding. Those bases are expected to increase the effect of repellent. Hence, related to repellan effect, the physical properties test of essential oils must be done to ensure purity and quality. Before performing repellent effects test, a physical properties test to obtain the best formula, i.e., a formula that can be applied topically with ease and comfort when it used. Essential oil of ginger rhizome and javanese turmeric rhizome are isolate by water and steam distillation methods and tested for physical properties, which consists of organoleptic test, refractive index and specific weight.
\end{abstract}

\footnotetext{
Penulis korespondesi:

Siti Fatmawati Fatimah

Fakultas Farmasi Universitas Ahmad Dahlan

Jl. Prof. Dr. Soepomo, S.H., Yogyakarta

Email: Fatmafatima28@gmail.com
} 
Repellent made in different concentrations, that are $2 \% \mathrm{v} / \mathrm{w}, 5 \% \mathrm{v} / \mathrm{w}, 10 \% \mathrm{v} / \mathrm{w}, 15 \% \mathrm{v} / \mathrm{w}, 20 \% \mathrm{v} / \mathrm{w}$, and $25 \% \mathrm{v} / \mathrm{w}$, then performed a test of the power spread, sticky ability, and viscosity.

The higher concentration of essential oil's cause wider spread ability, but smaller viscosity and stick ability. The selected formula is a formula with $25 \%$ w/v concentration, because it has wider spread ability and smaller viscosity so the repellent just need a little effort to rub with smaller stick ability so it's easy to be clean.

Keywords: essential oil, javanese turmeric rhizome, ginger rhizome, repellent, physical properties test

\section{PENDAHULUAN}

Rimpang jahe (Zingiber officinale Roxb. Rhizome) dan rimpang temulawak (Curcuma xanthorrhiza roxb. Rhizome) merupakan bahan herbal yang memiliki kandungan minyak atsiri. Secara teoritis, beberapa senyawa yang terdapat dalam minyak atsiri dapat berperan sebagai penolak serangga yang merusak tanaman, sehingga memungkinan jika minyak atsiri yang terkandung dalam rimpang temulawak dan rimpang jahe dapat menghalangi gigitan nyamuk atau berfungsi sebagai repelan. Namun, karena sifat iritatif dari miyak atsiri rimpang jahe lebih besar dan secara ekonomis harga rimpang jahe lebih mahal, maka untuk mengatasinya dilakukan kombinasi dengan rimpang temulawak. Adanya kombinasi ini diharapkan diperoleh sediaan repelan yang nyaman, aman, dan ekonomis saat digunakan.

Penelitian serupa mengenai repelan kombinasi minyak atsiri rimpang temulawak dan rimpang jahe telah dilakukan dengan menggunakan basis vanishing cream. Hasil penelitian tersebut menunjukkan waktu penolakan selama 32,54 menit dengan konsentrasi 25\% v/b (Afifah, 2007). Telah diketahui bahwa basis vanishing cream mempunyai fase minyak lebih sedikit dibanding dengan basis cold cream yang menyebabkan minyak atsiri menjadi lebih mudah menguap sehingga aktifitas repelan tidak optimal. Dalam penelitian ini, digunakan basis cold cream. Fase minyak pada basis cold cream lebih banyak dibandingkan pada basis vanishing cream, sehingga diharapkan minyak atsiri dapat dilepaskan secara perlahan sehingga efek repelan diharapkan mejadi lebih lama.

Fungsi repelan minyak atsiri salah satunya dipengaruhi oleh kualitas minyak atsiri. Oleh karenanya, tujuan dari penelitian ini adalah memastikan kualitas minyak atsiri sehingga dapat memberikan efek optimal sebagai repelan. Di samping itu, perlu dilakukan pemastian bahwa sediaan repelan yang diformulasikan dapat diaplikasikan dengan konsistensi yang lunak sehingga mudah diambil, nyaman, mudah dioleskan pada kulit manusia dan mudah dibersihkan.

Pada tahap awal perlu dilakukan pemastian kualitas minyak atsiri melalui uji sifat fisik minyak atsiri. Uji sifat fisik tersebut terdiri dari uji organoleptik, penetapan indeks bias, dan penetapan berat jenis minyak atsiri. Kualitas minyak atsiri yang memenuhi persyaratan sifat fisik menunjukkan kemurnian minyak atsiri dan diharapkan mampu memberikan efek repelan secara optimal. Pemastian kualitas sediaan repelan sehingga mudah dan nyaman untuk diaplikasikan dilakukan dengan pengujian sifat fisik repelan dalam berbagai konsentrasi minyak atsiri. Pengujian tersebut terdiri dari uji daya sebar, daya lekat, dan viskositas.

\section{METODE PENELITIAN Alat dan Bahan}

Alat yang digunakan adalah alat destilasi uap dan air, alat pembuatan basis cold cream, alat uji sifat fisik repelan yaitu alat uji daya sebar, daya lekat, dan alat uji viskositas (viskosimeter brook field). Bahan yang digunakan adalah minyak atsiri rimpang temulawak, minyak atsiri rimpang jahe, basis cold cream.

\section{Cara Kerja}

Identifikasi, pengumpulan dan persiapan bahan

Identifikasi tanaman dilakukan di laboratorium Biologi UAD Yogyakarta dengan berpedoman buku Flora of Java (Backer, 1968). Rimpang temulawak dan Rimpang jahe berasal dari Srandakan 
Kabupaten Bantul Yogyakarta dibersihkan, dipotong melintang, diangin-anginkan di udara terbuka dan dikeringkan tidak langsung dibawah sinar matahari (ditutupi kain hitam pada bagian permukaannya).

\section{Isolasi dan penentuan kadar minyak atsiri}

Metode isolasi yaitu destilasi uap dan air. Penentuan kadar minyak atsiri dengan destilator Stahl dan dihitung rendemennya, replikasi sebanyak 3 kali. Perhitungan kadar minyak atsiri dilakukan menggunakan rumus berikut:

$$
\text { Perhitungan rendemen }(\text { kadar })=\frac{\text { Volumeminyakatsisri }(\mathrm{ml})}{\text { Berat nahan }(\mathrm{g})} \times 100 \%
$$

\section{Uji sifat fisik minyak atsiri}

Uji sifat fisik yaitu uji organoleptik (warna, bau dan rasa minyak atsiri), penetapan indeks bias minyak atsiri digunakan refraktometer $\mathrm{ABBE}$, dan penetapan berat jenis minyak atsiri digunakan piknometer. Perhitungan berat jenis minyak atsiri dilakukan menggunakan rumus berikut:

Berat jenis $=\frac{m 2-m 1}{10 \mathrm{ml} \text { minyak atsirí }}$

\section{Formulasi repelan}

Repelan kombinasi minyak atsiri rimpang temulawak dan jahe dibuat dengan mencampurkan minyak atsiri dengan perbandingan 1:1 sesuai konsentrasi $(\% \mathrm{v} / \mathrm{b})$ dan cold cream dalam keadaan dingin (Tabel I).

Tabel I. Formula Basis Cold Cream

\begin{tabular}{lc}
\hline \multicolumn{2}{c}{ Cold Cream } \\
\hline Cethyl Esters Wax & $12,5 \mathrm{~g}$ \\
Cerae albi & $12 \mathrm{~g}$ \\
Paraffini liquidi & $56 \mathrm{~g}$ \\
Natrii tetraboras & $0,5 \mathrm{~g}$ \\
Aquadest & $19 \mathrm{~mL}$ \\
\hline \multicolumn{2}{c}{ (Remington, 2000) }
\end{tabular}

Pembuatan basis cold cream (Tabel I) dilakukan dengan cara cera alba dileburkan dalam cawan porselen dan dalam cawan porselen yang berbeda, dileburkan pula cethyl esters wax dan paraffin liquidum. Peleburan dilakukan pada water bath dengan suhu $75{ }^{\circ} \mathrm{C}$. Bahan diaduk sampai melebur seluruhnya. Pada beker glass, natrii tetraboras dilarutkan dengan aquadest, kemudian hangatkan di water bath dengan suhu $75^{\circ} \mathrm{C}$ (agar diperoleh suhu leburan yang sama antar cera alba, cethyl esters wax, dan paraffin liquidum). Kemudian mortir dihangatkan dengan air panas. Hasil leburan cera alba, cethyl esters wax, paraffin liquidum dituang pada mortir hangat. Larutan hangat Natrii tetraboras dimasukkan dan dicampurkan perlahan, kemudian diaduk terus hingga terbentuk masa basis yang dingin

Tabel II. Pembuatan bahan uji berbagai konsentrasi

\begin{tabular}{cccc}
\hline \multirow{2}{*}{$\begin{array}{c}\text { Konsentrasi } \\
(\% \mathbf{v} / \mathbf{b})\end{array}$} & \multicolumn{3}{c}{ Mormula } \\
\cline { 2 - 3 } & Rimpang temulawak & Rimpang jahe & \multirow{2}{*}{ Cold cream } \\
\cline { 2 - 3 } & 0,05 & 0,05 & \\
\hline 2 & 0,125 & 0,125 & hingga 5 gram \\
5 & 0,75 & 0,75 & hingga 5 gram \\
10 & 0,375 & 0,375 & hingga 5 gram \\
15 & 0,50 & 0,50 & hingga 5 gram \\
20 & 0,625 & 0,625 & hingga 5 gram \\
25 & & hingga 5 gram \\
\hline
\end{tabular}




\section{Uji Sifat Fisik Repelan}

Uji daya sebar dilakukan dengan 0,5 gram repelan diletakkan di atas kaca bulat berskala, kemudian ditutup dengan menggunakan kaca bulat yang tidak berskala dengan bobot diketahui, selama 1 menit. Setelah itu, dicatat diameter penyebarannya, dan dilanjutkan menggunakan beban 50 gram, 100 gram. Uji daya sebar dilakukan sebanyak 3 kali.

Uji viskositas dilakukan dengan viskosimeter Brookfield. Sediaan repelan diletakkan dalam cup viskotester sebanyak $50 \mathrm{mg}$. Viskotester dihidupkan dengan kecepatan $2 \mathrm{rpm}$ dan rotor akan mulai bergerak atau berputar. Harga viskositas dibaca dalam skala centi poise (cps), replikasi 3 kali.

Uji daya lekat dilakukan dengan cara repelan diratakan pada objek glass dengan ukuran kurang lebih $3 \mathrm{~cm}$ x $2 \mathrm{~cm}$. Kemudian ditutup dengan objek glass lain, ditekan dengan beban seberat 1 $\mathrm{kg}$ selama 5 menit. Objek glass dipasang pada alat uji dilepas dengan beban seberat 80 gram dan waktu yang diperlukan untuk memisahkan kedua objek glass tersebut dicatat. Dilakukan replikasi sebanyak 3 kali untuk masing-masing konsentrasi.

\section{Analisis Data}

Data hasil uji sifat fisik (daya lekat, daya sebar dan viskositas) repelan diuji homogenitas dan diuji menggunakan Kolmogorov-smirnov. Bila data terdistribusi normal pada uji Kolmogorov-smirnov $(\alpha \geq 0,05)$ dan homogen pada uji homogenitas $(\alpha \geq 0,05)$, maka dilakukan uji parametrik one way Anova dan post hock test. Apabila tidak sesuai dengan ketentuan tersebut, dilanjutkan uji non parametrik Kruskal-Wallis dan Mann Whitney. Data berbeda bermakna bila pada uji parametrik atau pada uji non parametrik $\alpha \leq 0,05$.

\section{HASIL DAN PEMBAHASAN}

\section{Identifikasi, pengumpulan, dan persiapan bahan}

Identifikasi bertujuan memastikan rimpang yang digunakan adalah benar-benar rimpang temulawak (Curcuma xanthorrhiza Roxb. Rhizome) dan rimpang jahe (Zingiber officinale Roxb. Rhizome ) dan hasil identifikasi memang terbukti demikian.

Pengambilan bahan baku dilakukan pada musim kemarau karena pada saat ini rimpang menghasilkan metabolit sekunder (salah satunya minyak atsiri) secara maksimal. Rimpang berupa simplisia kering, denganrajangan melintang dan telah dibersihkan. Pengeringan dimaksudkan untu mengurangi kelembapan agar kualitas tetap baik, tidak terjadi pertumbuhan jamur dan kapang, mencegah aktivitas enzim yang mungkin menyebabkan terjadinya perubahan kandungan kimia, serta memudahkan pelarut masuk ke dalam setiap bagian sehingga penyulingan berjalan efisien. Penyulingan minyak atsiri dengan metode uap dan air berhasil dilakukan bila uap air melalui jaringan tanaman, kemudian mendesaknya ke permukaan atau proses hidrodifusi. Proses ini akan berlangsung sangat lambat apabila bagian tanaman dibiarkan dalam keadaan utuh, tetapi apabila perajangan terlalu tipis menyebabkan berkurangnya atau hilangnya zat berkhasiat yang mudah menguap. Bentuk rajangan sebaiknya melintang agar permukaannya lebih luas sehingga dapat mempercepat proses penguapan.

\section{Isolasi dan penentuan kadar minyak atsiri}

Proses isolasi minyak atsiri dilakukan oleh LPPT Universitas Gadjah Mada. Isolasi minyak atsiri atau penyulingan adalah proses pemisahan komponen yang berupa padatan atau cairan dari 2 macam campuran atau lebih, berdasar perbedaan titik uapnya. Proses ini dilakukan pada minyak atsiri yang tidak larut air. Isolasi minyak atsiri menggunakan metode destilasi uap dan air. Tapak-tapak air dihilangkan dengan penambahan natrium sulfat anhidrat $\left(\mathrm{Na}_{2} \mathrm{SO}_{4}\right)$. Minyak atsiri yang diperoleh diukur volumenya dan ditampung dalam wadah gelap tertutup rapat (flakon gelap) dibungkus alumunium foil dikarenakan minyak atsiri dapat mengalami kerusakan akibat pengaruh cahaya.

Alat yang digunakan yaitu destilator stahl. Suhu alat diatur sehingga destilat yang keluar dapat menetes teratur. Pemanasan terlalu tinggi akan menyebabkan destilat menetes cepat dan akan teruap kembali, dan bila terlalu dingin, maka waktu destilasi akan lama sehingga tidak efisien. 
Hasil destilasi (Tabel III) diperoleh rendemen rata-rata minyak atsiri rimpang temulawak $(5,067$ $\pm 0,058) \% \mathrm{v} / \mathrm{b}$ sesuai dengan teori sebesar 3-12\% v/b (Anonim, 2013). Sedangkan rendemen rimpang jahe $(2,233 \pm 0,058) \% \mathrm{v} / \mathrm{b}$. Hasil ini sesuai dengan spesifikasi, bahwa kadar minyak atsiri rimpang jahe sebesar 1,5-3,0\% v/b (Anonim, 2002). Hasil tersebut menunjukkan bahwa minyak atsiri yang didestilasi merupakan minyak atsiri murni dari rimpang temulawak dan rimpang jahe.

Tabel III. Data Hasil Rendemen Minyak Atsiri

\begin{tabular}{cccc}
\hline Sampel & Berat kering (gram) & Volume minyak atsiri $(\mathbf{m L})$ & Kadar ( \% v/b) \\
\hline Rimpang & 5,00 & 0,250 & 5,00 \\
temulawak & 5,00 & 0,255 & 5,10 \\
& 5,00 & 0,255 & 5,10 \\
& Rata- rata \pm SD & $0,2533 \pm 0,003$ & $5,067 \pm 0,058$ \\
Rimpang & 5,00 & 0,110 & 2,20 \\
Jahe & 5,00 & 0,110 & 2,20 \\
& 5,00 & 0,115 & 2,30 \\
& Rata- rata \pm SD & $0,112 \pm 0,003$ & $2,233 \pm 0,058$ \\
\hline
\end{tabular}

\section{Uji sifat fisik minyak atsiri}

Uji organoleptis minyak atsiri rimpang temulawak mempunyai bau khas aromatik, jernih, dan rasa tajam, pedas. Minyak atsiri rimpang jahe mempunyai bau khas aromatik, jernih agak kekuningan, dan rasa tajam, pedas. Pemeriksaan bersifat subjektif (belum menggambarkan kemurnian minyak atsiri secara tepat).

Indeks bias adalah perbandingan kecepatan cahaya dalam hampa udara dengan kecepatan cahaya dalam zat tersebut dengan menggunakan refraktometer ABBE. Hasil pengukuran indeks bias minyak atsiri rimpang temulawak adalah 1,5004 dan indeks bias minyak atsiri rimpang jahe adalah 1,4844. Hasil ini tidak jauh berbeda dengan indeks bias standar minyak atsiri rimpang temulawak yaitu 1,5024-1,5070 (Perhiba, 1989) dan indeks bias standar minyak atsiri rimpang jahe yaitu 1,488-1,494 (Anonim, 2002). Hal ini dimungkinkan karena perbedaan tempat tumbuh tanaman dengan standar. Analisis indeks bias digunakan untuk memeriksa pemalsuan mutu dan kemurnian minyak atsiri. Jika minyak atsiri disimpan lama dan dalam kondisi yang tidak baik, komponen dalam minyak atsiri dapat teroksidasi sehingga menghasilkan minyak yang lebih kental, warna lebih gelap dan akhirnya membentuk sejenis damar. Hal ini akan menyebabkan perubahan nilai indeks biasnya.

Tabel IV. Data berat jenis minyak atsiri

\begin{tabular}{cccc}
\hline Sampel & Volume minyak $(\mathbf{m L})$ & Berat minyak (gram) & Berat jenis $($ gram/ ml) \\
\hline Rimpang & 10,0 & 9,4364 & 0,94364 \\
temulawak & 10,0 & 9,4324 & 0,94324 \\
& 10,0 & 9,4375 & 0,94375 \\
Rimpang jahe & Rata- rata \pm SD & $9,4354 \pm 0,003$ & $0,9435 \pm 0,0003$ \\
& 10,0 & 9,160 & 0,9160 \\
& 10,0 & 9,178 & 0,9178 \\
& 10,0 & 9,175 & 0,9175 \\
& Rata- rata \pm SD & $9,171 \pm 0,0096$ & $0,9171 \pm 0,001$ \\
\hline
\end{tabular}

Berat jenis adalah perbandingan bobot zat terhadap air suling volume sama yang ditimbang di udara pada suhu yang sama dan merupakan kriteria penting dalam menentukan mutu dan kemurnian minyak atsiri. Berdasar Tabel IV, nilai berat jenis minyak atsiri rimpang temulawak adalah $(0,9435 \pm$ $0,0003) \mathrm{gram} / \mathrm{mL}$ dan rimpang jahe $(0,9171 \pm 0,001) \mathrm{gram} / \mathrm{mL}$. Nilai berat jenis kedua minyak atsiri tersebut memenuhi persyaratan antara $(0,696-1,188) \mathrm{gram} / \mathrm{mL}$ pada suhu $15{ }^{\circ} \mathrm{C}$ dan pada umumnya nilai tersebut lebih kecil dari 1,000 gram/mL untuk setiap jenis minyak (Guenter, 1952).

\section{Pembuatan bahan uji}

Bahan uji terdiri cold cream dengan kombinasi minyak atsiri rimpang temulawak dan rimpang jahe. Kelebihan cold cream yaitu konsistensinya yang lebih kental, lebih lama menempel di kulit 
dibandingkan losion, sehingga diharapkan dapat menimbulkan efek lebih lama (mempunyai waktu proteksi terhadap gigitan nyamuk lebih lama). Di samping itu, salep sejuk (cold cream) cukup banyak mengandung air, sehingga menimbulkan efek sejuk. Efek sejuk dari proses penguapan air karena untuk terjadi penguapan diperlukan panas dari panas tubuh, sehingga menimbulkan efek sejuk pada kulit (Banker dan Rhodes, 2009). Kekurangan dari basis salep cold cream yaitu lebih sukar dicuci dengan air bila dibandingkan dengan losion.

Metode pembuatan basis yaitu metode peleburan, yaitu dengan cara cera alba, cethyl esters wax, dan paraffin liquidum dileburkan di atas water bath dengan suhu $75{ }^{\circ} \mathrm{C}$. Natrii tetraboras dalam aquadest dihangatkan pada water bath dengan suhu yang sama. Apabila tidak dilakukan pada suhu yang sama, maka saat pencampuran leburan cera alba, cethyl esters wax, dan paraffin liquidum akan cepat kembali kebentuk padatan kemudian terjadi penggumpalan sehingga diperoleh basis yang kasar. Pencampuran bahan dilakukan pada mortir hangat. Basis disimpan ditempat kering, terhindar sinar matahari dan ditempat yang sejuk. Pencampuran minyak atsiri dengan basis dilakukan pada saat dingin untuk menghindari penguapan minyak atsiri (Banker dan Rhodes, 2009).

Formula repelan dibagi menjadi 6 kelompok konsentrasi yaitu $2 \%$ v/b, 5\% v/b, 10\% v/b, $15 \%$ $\mathrm{v} / \mathrm{b}, 20 \% \mathrm{v} / \mathrm{b}$, dan $25 \% \mathrm{v} / \mathrm{b}$. Perbandingan minyak atsiri rimpang temulawak dan rimpang jahe 1:1. Pemilihan konsentrasi berdasarkan hasil orientasi. Jika lebih besar $25 \% \mathrm{v} / \mathrm{b}$, basis dan minyak atsiri tidak tercampur homogen dan sediaan tidak stabil yaitu terpisahnya minyak atsiri bagian atas dan basis bagian bawah.

\section{Uji Sifat Fisik}

Uji dilakukan untuk menjamin kualitas farmasetik karena sangat berhubungan dengan kenyamanan pemakai dalam penggunaan dan kemampuan proteksinya terhadap gigitan nyamuk. Uji daya sebar mencerminkan kemampuan menyebar pada kulit, sehingga diharapkan sediaan yang dihasilkan mudah menyebar tanpa penekanan berarti. Semakin luas penyebaran pada kulit semakin baik sediaan tersebut.

Tabel V. Data uji sifat fisik daya sebar

\begin{tabular}{cc}
\hline $\begin{array}{c}\text { Konsentrasi } \\
(\%) \mathbf{v} / \mathbf{b}\end{array}$ & Luas daya sebar $\left(\mathbf{c m}^{\mathbf{2}}\right)$ \\
\cline { 2 - 2 } 2 & Rata-rata $\mathbf{\text { SD }}$ \\
5 & $8,729 \pm 0,599$ \\
10 & $14,196 \pm 1,193$ \\
15 & $16,759 \pm 1,357$ \\
20 & $16,774 \pm 2,035$ \\
25 & $17,282 \pm 2,596$ \\
\hline
\end{tabular}

Data menunjukkan semakin tinggi konsentrasi minyak atsiri maka semakin luas daya sebarnya. Hal ini dikarenakan kandungan minyak atsiri yang bertambah banyak menyebabkan konsistensi sediaan menjadi lebih encer sehingga lebih mudah menyebar dan daerah penyebarannya menjadi lebih luas. Daerah penyebaran yang lebih luas dikhawatirkan menyebabkan pelepasan minyak atsiri menjadi lebih cepat sehingga berakibat pada penurunan aktifitas repelan (waktu efektif tolak nyamuk). Namun berdasar pada (Fatimah et al., 2014) repelan kombinasi minyak atsiri rimpang jahe dan temulawak pada basis cold cream menunjukkan semakin tinggi konsentrasi minyak atsiri, semakin lama pula waktu efektif tolak nyamuknya. Hal tersebut dikarenakan basis cold cream adalah tipe emulsi air dalam minyak (A/M). Adanya fase minyak yang lebih banyak berakibat pada pengikatan minyak atiri yang lebih optimal dan lebih kuat. Ikatan antara fase minyak dengan minyak atsiri tersebut dapat berperan dalam upaya meminimalisir kecepatan pelepasan minyak atsiri. Selain itu, daya sebar yang luas memberikan keuntungan mempermudah proses aplikasi repelan. Hal ini dikarenakan dengan sedikit usaha repelan dapat diolehkan dengan mudah dikulit.

Analisis data dilakukan menggunakan prosedur statistik parametrik. Hasil analisa menunjukkan jika masing-masing kelompok uji berbagai konsentrasi dibandingkan, menunjukkan 
perbedaan yang signifikan (bermakna) pada konsentrasi $2 \% \mathrm{v} / \mathrm{b}$ dengan $10 \% \mathrm{v} / \mathrm{b}, 2 \%$ v/b dengan $15 \%$ $\mathrm{v} / \mathrm{b}, 2 \% \mathrm{v} / \mathrm{b}$ dengan $20 \% \mathrm{v} / \mathrm{b}, 2 \% \mathrm{v} / \mathrm{b}$ dengan $25 \% \mathrm{v} / \mathrm{b}, 5 \% \mathrm{v} / \mathrm{b}$ dengan $25 \% \mathrm{v} / \mathrm{b}$, dan $10 \% \mathrm{v} / \mathrm{b}$ dengan $25 \% \mathrm{v} / \mathrm{b}$. Hasil ini menunjukkan dengan adanya perubahan konsentrasi minyak atsiri tersebut menimbulkan perbedaan atau pengaruh berarti pada daya sebarnya.

Uji Daya lekat merupakan kemampuan sediaan untuk melekat pada kulit. Kemampuan melekat lebih lama pada kulit memungkinkan zat aktif dapat memberikan efek yang sempurna. Hasil uji pada Tabel VI menunjukkan semakin tinggi konsentrasi minyak atsiri maka semakin singkat waktu lekatnya. Hal ini dikarenakan kandungan minyak atsiri bertambah banyak sehingga konsistensinya menjadi lebih encer yang menyebabkan waktu lekat lebih singkat. Idealnya, sediaan repelan memiliki daya lekat yang lama, karena lamanya daya lekat memperngaruhi lamanya waktu menempel repelan pada kulit. Semakin lama waktu lekatnya maka semakin optimal pula pelepasan minyak atsiri sehingga waktu efektif tolak nyamuknya menjadi lebih lama. Namun pada penelitian sebelumnya, repelan kombinasi minyak atsiri rimpang jahe dan temulawak pada basis cold cream menunjukkan bahwa semakin tinggi konsentrasi minyak atsiri, semakin lama pula waktu efektif tolak nyamuknya (Fatimah et al., 2014). Berdasar hasil tersebut maka daya lekat yang singkat tidak berkorelasi langsung dengan lama waktu efektif tolak nyamuk.

Di sisi lain, beberapa keuntungan dari waktu lekat yang singkat yaitu repelan menjadi lebih mudah mengalir sehingga mudah dikeluarkan dari wadah kemasan. Di samping itu, dapat mengatasi kelemahan basis yang tidak mudah dicuci dengan air. daya lekat yang rendah menyebabkan repelan lebih mudah dibersihan dengan air, sehingga tujuan diperoleh formulasi repelan yang mudah dituang dan nyaman untuk diaplikasikan ke pengguna dapat tercapai.

Tabel VI. Data uji sifat fisik daya lekat

\begin{tabular}{cc}
\hline $\begin{array}{c}\text { Konsentrasi } \\
(\%) \mathbf{v} / \mathbf{b}\end{array}$ & Waktu daya lekat (detik) \\
\cline { 2 - 2 } 2 & Rata-rata $\mathbf{S D}$ \\
5 & $8,563 \pm 0,271$ \\
10 & $8,373 \pm 0,462$ \\
15 & $4,693 \pm 0,150$ \\
20 & $2,450 \pm 0,260$ \\
25 & $1,680 \pm 0,000$ \\
\end{tabular}

Analisis data dilakukan menggunakan prosedur statistika non parametrik. Jika masing-masing kelompok uji berbagai konsentrasi dibandingkan menunjukkan perbedaan signifikan (bermakna). Hal ini menunjukkan dengan adanya peningkatan konsentrasi minyak atsiri menimbulkan perbedaan yang berarti pada daya lekatnya. Hasil tersebut tidak berlaku pada konsentrasi $2 \% \mathrm{v} / \mathrm{b}$ dengan $5 \% \mathrm{v} / \mathrm{b}$ dan $2 \% \mathrm{v} / \mathrm{b}$ dengan $15 \% \mathrm{v} / \mathrm{b}$ yang menunjukkan hasil berbeda tidak signifikan.

Sediaan repelan sebaiknya memiliki konsistensi yang lunak sehingga mudah diaplikasikan. Konsistensi repelan dapat diukur melalui uji viskositas. Semakin kecil viskositas, semakin lunak konsistensi repelan (semakin encer). Konsistensi yang lebih lunak memberikan kenyamanan bagi pengguna repelan karena repelan menjadi lebih mudah diaplikasikan secara merata ke kulit tanpa menggunakan tekanan atau usaha berlebih. Data uji viskositas pada Tabel VII menunjukkan semakin tinggi konsentrasi minyak atsiri, semakin kecil viskositasnya. Hal tersebut dikarenakan kandungan minyak atsiri bertambah banyak sehingga konsistensinya menjadi lebih lunak (encer). 
Tabel VII. Data uji sifat fisik viskositas

\begin{tabular}{cc}
\hline $\begin{array}{c}\text { Konsentrasi } \\
(\% \mathbf{~ v / b})\end{array}$ & Viskositas $(\mathbf{c p s})$ \\
\cline { 2 - 2 } & Rata-rata \pm SD \\
\hline 2 & $226,9 \pm 11,911$ \\
10 & $213,6 \pm 1,512$ \\
15 & $205,4 \pm 5,685$ \\
20 & $198,2 \pm 1,528$ \\
25 & $186,8 \pm 2,921$ \\
\hline
\end{tabular}

Analisis data dilakukan menggunakan prosedur statistika parametrik. Jika masing-masing kelompok uji berbagai konsentrasi dibandingkan menunjukkan perbedaan signifikan (bermakna). Hal ini menunjukkan dengan adanya peningkatan konsentrasi minyak atsiri menimbulkan perbedaan yang berarti pada viskositasnya. Hasil tersebut tidak berlaku pada konsentrasi $10 \% \mathrm{v} / \mathrm{b}$ dengan $15 \% \mathrm{v} / \mathrm{b}$ yang menunjukkan hasil berbeda tidak signifikan.

\section{KESIMPULAN}

Semakin tinggi konsentrasi minyak atsiri pada repelan minyak atsiri kombinasi rimpang temulawak dan rimpang jahe dengan basis cold cream menyebabkan daya sebar semakin luas, namun viskositas dan daya daya lekat semakin kecil. Formula yang dipilih adalah formula dengan konsentrasi 25\% karena memiliki daya sebar yang luas dan viskositas yang kecil sehingga dengan sedikit usaha repelan dapat dioleskan dengan mudah dikulit serta daya lekat yang kecil sehingga mudah untuk dituang dan dibersihkan.

\section{DAFTAR PUSTAKA}

Anonim, 2002, Ginger: Post- Harvest Operations, Food and Agriculture Organization (FAO) of the United Nation, USA, 15.

Anonim, 2013, Assessment Report on Curcuma xanthorrhiza Roxb. (C. xanthorrhiza D. Dietrich)., rhizoma, European Medicine Agency, United Kingdom, 3.

Afifah, R. A., 2007, Uji Aktivitas Repelan Cream Kombinasi Minyak Atsiri Rimpang Temulawak dan Rimpang Jahe dalam Basis Vanishing Cream terhadap Nyamuk Aedes aegypti, Skripsi, Fakultas Farmasi, UAD Yogyakarta.

Backer, C.A., Brink, V.D.R.C., 1968, Flora of Java, Publised under the auspices of the rijksherbarium, Leyden.

Banker, G.S. dan Rhodes, C.T., 2009, Modern Pharmaceutics, Informa Heathcare Inc, New York, 77.

Guenther, E., 1952, The Essential Oil, van Nostran Reinhold Company, New York, 115, 125, 236.

Fatimah, S. F., Widyaningsih, W., Ikhsanudin, A., 2014, Efek Repelan Kombinasi Minyak Atsiri Rimpang Temulawak (Curcuma xanthorrhiza Roxb. Rhizome) Dan Rimpang Jahe (Zingiber officinale Roxb. Rhizome ) dalam Basis Unguentum Leniens terhadap Nyamuk Aedes aegypti, Jurnal Farmasi Indonesia, Universitas Muhammadiyah Purwokerto.

Perhimpunan Peneliti Obat Alami, 1989, Seri Tanaman Obat, Empon-empon dan Tanaman Lain dalam Zingiberaceae, IKIP Press, Semarang, 31-33.

Remington, 2000, The Science and Practice of Pharmacy $20^{\text {th }}$ Edition, Lippincot Williams \& Wilkins : Maryland, 1036. 